\title{
Women and Health: Women's Dual Roles as Both Recipients and Providers of Healthcare
}

\author{
Afaf I. Meleis, PhD, DrPS(hon), FAAN, Jacquelyn Caglia, MPH, and Ana Langer, $\mathrm{MD}^{2}$
}

\begin{abstract}
With the many economic, demographic, social and epidemiological global transitions, a Harvard-Penn-Lancet commission reviewed the current health status of women and its relationship to sustainability, and redefined the field as women and health. Four major recommendations were offered, insuring mechanisms to count women properly as providers and recipients of care, to value them by insuring protective policies, to treat and compensate them fairly and equitably, and to develop strategies to be accountable for sustaining and implementing the recommendations. However, without a life span approach to women, and their health, and without universal access to comprehensive health care, women's wellbeing and abilities to function up to their full capacities will be compromised. These recommendations have many implications for health care, education and practice.
\end{abstract}

$\mathbf{T}$ HE FIELD OF WOMEN's health has undergone many changes, evolving from a biomedical framework, expanding from maternal and newborn health to sexual and reproductive health, to acknowledging the influence social determinants, rights, and equity have on health, to incorporating the environment and sustainability as conditions in planning for and implementing healthcare for women. In spite of robust international dialogues that have driven and contributed to these changes, women's health continues to be reduced to reproductive care, as evidenced by the nature of education provided to healthcare professionals, the allocation of funds, and the provision of health service resources.

A recent 2015 report in The Lancet, "Women and Health: the key for sustainable development," advocates for redefining the field of women's health, which may be the catalyst in changing the paradigm that informs education, practice, and research related to women and their health. This publication is the outcome of deliberations and writings of a commission composed of 14 members from 13 countries representing many different disciplines and roles in healthcare, including academicians, clinicians, advocates, policy makers, writers, and scientists. They chose to redefine women's health as women and health, and in doing so, they proposed to make healthcare for women more inclusive of women's life cycles, environments, and healthcare needs and fully recognized the critical roles women play as healthcare providers in the home, in their communities, and in the healthcare system. The report addresses the link between women's health and sustainability of environments as well and between women's roles as both consumers and producers of healthcare.

While commissioners started from the premise that universal healthcare is an essential condition for the quality care of women, they also provided the rationale for basing women and health approaches on a fundamental premise of women's rights to be treated equitably, not only in their health and healthcare but also in all of their roles. To deal with the many challenges they face, women are entitled to enabling environments that support and facilitate their abilities to meet the demands of their daily roles and responsibilities. These are fundamental requirements to ensure women's health and well-being.

Women enact many formal and informal roles in the society. Many of these roles are unacknowledged, unrewarded, and undercompensated. The demands on women challenge their time and energy and, in turn, directly and indirectly impact their health and well-being, as well as their access to healthcare. Putting them at risk for stress and illness, some of these factors are compensation inequity, devaluation of their unpaid

\footnotetext{
${ }^{1}$ Department of Family and Community Health, University of Pennsylvania School of Nursing, Philadelphia, Pennsylvania.

${ }^{2}$ Maternal Health Task Force and Women and Health Initiative, Department of Global Health and Population, Harvard T.H. Chan School of Public Health, Boston, Massachusetts.

This article was developed during AIM's residency at The Rockefeller Foundation, Bellagio Center in Bellagio, Como, Italy.

(c) Afaf I. Meleis, et al. 2016; Published by Mary Ann Liebert, Inc. This Open Access article is distributed under the terms of the Creative Commons Attribution Noncommercial License (http://creativecommons.org/licenses/by-nc/4.0/) which permits any noncommercial use, distribution, and reproduction in any medium, provided the original author(s) and the source are credited.
} 
contributions to healthcare and to their communities, inhospitable environments that lack resources to support their roles, lack of attention to the effects of increasing noncommunicable diseases, and degradation in living environments, all of which are adding to women's burdens in managing their daily responsibilities and roles inside and outside of their homes. These stressors render women more vulnerable to illness and health issues.

This proposed redefinition of women and health is timely and urgent because of many global transitions that are affecting and will continue to affect the health of women. Among these transitions are increasing globalization, which is facilitating the immigration of women to seek better educational and occupational opportunities for themselves and their children, and contributing to the spread of communicable diseases across continents. Along with increasing globalization, there is an increase in the development of urban areas and megacities to accommodate immigrants and migrants, and with this urbanization, there is an increase in slums, shanty cities, and makeshift housing. Women tend to live in these deprived areas, as they make up for $70 \%$ of the poor population. These transitions, with limited resources for environmental preservation and renewals, are creating environmental waste, climate change, and many hazards that tend to excessively affect those who live in poor, built-up congested areas.

Urbanization, economic, environmental, and epidemiological transitions are influencing how women experience their health and well-being, as well as how they function in their roles. With immigration and migration, there is an erosion of social capital and dislocation in the support that is usually provided by families and communities. This contributes to increasing lifestyle risks and it limits women's abilities to negotiate abusive relations and leave intimate partner violence situations. The environmental degradations and the unsafe environments, created by poor lighting, unsafe transportation, and escalated violence, increase women's health risks.

Women continue to bear the burden of caring for others and the major burden of health needs within their households and communities. In spite of increased responsibilities and demands on their time, women bear $90 \%$ of the paid and unpaid caregiving roles in the world. In 2010, women contributed the equivalent of $2.35 \%$ of the overall global Gross Domestic Product for their unpaid work and $2.47 \%$ for their paid work. This translates into more than 3 trillion U.S. dollars annually. ${ }^{1}$ As women entered the varied occupational spheres outside their homes, their caregiving and home life roles, responsibilities, and management did not decrease to make room for their occupational demands. The work environment did not change to allow women to carry their daily life responsibilities and their new, added occupational responsibilities. For example, more women are entering medicine globally (in the United Kingdom, about $70 \%$ of medical school intakes are women), yet, fewer women physicians than men physicians opt to practice medicine due to the additional demands on their time caused by the extra roles and obstacles straining their environments. ${ }^{1}$ Conversations with young physicians with families, who are recruited to academic roles, affirm the incompatibility of the multiple roles they choose to carry to manage their families with their inflexible work situations.
It is important to also note that $80 \%$ of the healthcare giving in the world is provided by nurses who number about 20 million globally, $90 \%$ of whom are women who encounter the same issues all women face. ${ }^{1,2}$ Women's roles and burdens are increased with global transitions, particularly when they live and work in environments that are not responsive to their multiple roles and responsibilities, and consequently, to their healthcare needs.

There is also a global shift from communicable to noncommunicable diseases created by globalization, urbanization, limited economic support, increased processed food consumption, decreased fresh produce access, increased polluted living environments, and depleted households. While communicable diseases such as malaria and HIV continue to infect women disproportionately, women also suffer from noncommunicable diseases.

Leading causes of morbidities by gender for female embryos, infant girls, girl children, and women are different from boys and men due to the intersection of biology and sociocultural factors. In some parts of the world such as India and China, sex selection during pregnancy has led to decrease in the number of females. In many developing countries, girl children are neglected, with limited access to good nutrition and delays in healthcare. Leading causes of morbidities and mortalities for adolescent girls are self-harm, maternal disorders, and accidents. ${ }^{1}$ Many of the lifestyle patterns that put girls at risk, such as alcohol use, tobacco use, and limited physical activity, begin during adolescent years. While maternal deaths were halved since the declaration of the Millennium Development Goals, self-harm, road injuries, cardiovascular disease, depressive disorders, stroke, and lower back pain are on the rise and now ranked in the 10 leading causes of death for women. ${ }^{3}$ Lifestyle changes mandated by poverty and urbanization lead to risks for diabetes, asthma, and cardiovascular diseases.

Women's health requires that we change our conceptualization of women as recipients and as providers of healthcare, instead of only on women on the receiving end of care. The education of healthcare professionals promotes professional silos and lacks focus and attention to determinants of health, women's productive roles, their needs to manage their daily lives, and how unfriendly and unresponsive environments affect them. The overall burden of disease increases for women as caregivers and recipients of care. While women in general are challenged with unequal healthcare, economic, cultural, and urban transitions make minorities such as lesbians, immigrants, and migrants even more vulnerable to health risks.

The commission made several recommendations beginning with the assertion that women must have universal access to comprehensive healthcare developed and implemented within a justice and equity framework. In addition, the "count women" recommendation calls for the global community, governments, organizations, and families to value and acknowledge women and to develop mechanisms to ensure that women and girls are counted in every position in life, including at birth, in schools, in homes, and in all occupations. The purpose for counting women is to detect inequalities. For example, counting how many women are admitted and graduate in schools of medicine raises conscious questions about the gender imbalance and prompts solutions.

A second recommendation is to value women by developing gender responsive policies that support women's 
productive roles that ensure they are able to work up to their full capacities and that they have choices that promote their physical and mental health. Moreover, these policies need to address the entire life course instead of honing in on reproductive years and reproductive health.

A third recommendation, equally, if not more vital for women and health, is to compensate women fairly and equitably for their formal and informal roles. To promote health and well-being, as Marmot said, "We cannot ignore unfair economic arrangements." 4 Countries and organizations should establish mechanisms to evaluate compensation of women at all levels to determine whether they are receiving pay that equals their efforts and that it is equal to men's compensation performing the same roles. Compensation is a measure of valuation in societies for the work that women do and it provides women with purchasing powers. Caregiving support, formal or informal, should be acknowledged, valued, and compensated.

It is not simply enough for policies to say women should be acknowledged, valued, and compensated. To sustain the changes created by the recommendations, mechanisms and systems should be developed to be accountable to women. Practices, indicators, and measurement tools need to be put in place to safeguard the acknowledgment, valuations, and equitable compensation for women. Accountability includes identifying indicators of progress and criteria for measuring that progress and its impact, as well as developing systems to implement equitable policies and monitor and evaluate progress. Moreover, research and dissemination of research should be based on sex and gender differences, and editors must develop accountable review processes to accept publications that reflect those differences and reject publications that do not take sex and gender into consideration.

\section{Author Disclosure Statement}

No competing financial interests exist.

\section{References}

1. Langer A, Meleis A, Knaul F, et al. (in press). Women and Health: The key for sustainable development. Lancet 2015; 386:1165-1210.

2. The World Bank. The World Bank's Open Data Initiative Website, 2015. Available at: http://datacatalog.worldbank.org/ Accessed July 21, 2015.

3. World Health Organization. WHO Health Topics Website, 2015. Available at: www.who.int/topics/millennium_ development_goals/en/ Accessed July 21, 2015.

4. Marmot M. Health equity: The challenge. Aust N Z J Public Health 2012;36:513-514.

Address correspondence to:

Afaf I. Meleis, PhD, DrPS(hon), FAAN Department of Family and Community Health University of Pennsylvania School of Nursing 420A Claire M. Fagin Hall 418 Curie Boulevard Philadelphia, PA 19104-4217

E-mail: meleis@nursing.upenn.edu 